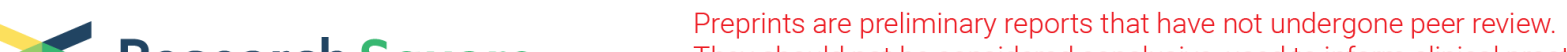 Research Square
or referenced by the media as validated information.
}

\section{Factors Associated with a Malaria Outbreak at Tongogara Refugee Camp in Chipinge District, Zimbabwe, 2021: A Case-Control Study}

\section{Kudzai Patience Takarinda}

University of Zimbabwe Faculty of Medicine: University of Zimbabwe College of Health Sciences

Simon Nyadundu

Ministry of Health and Child Care

Emmanuel Govha

University of Zimbabwe

Addmore Chadambuka ( $\square$ achadambuka1@yahoo.co.uk)

University of Zimbabwe College of Health Sciences https://orcid.org/0000-0003-2407-1172

Notion Tafara Gombe

University of Zimbabwe

\section{Tsitsi Patience Juru}

University of Zimbabwe

\section{Mufuta Tshimanga}

University of Zimbabwe Faculty of Medicine: University of Zimbabwe College of Health Sciences

\section{Research Article}

Keywords: Malaria outbreak, Tongogara Refugee Camp, refugee housing unit, Zimbabwe

Posted Date: December 15th, 2021

DOI: https://doi.org/10.21203/rs.3.rs-1061568/v2

License: (9) This work is licensed under a Creative Commons Attribution 4.0 International License.

Read Full License

Version of Record: A version of this preprint was published at Malaria Journal on March 19th, 2022. See the published version at https://doi.org/10.1186/s12936-022-04106-9. 


\section{Abstract}

Background: Malaria is a leading cause of morbidity and mortality among forcibly displaced populations including refugees, approximately two-thirds of whom reside in malaria endemic regions. Data from the rapid disease notification system (RDNS) reports for Manicaland Province in Zimbabwe showed that despite implementation of malaria control initiatives, there was an increase in number of malaria cases above action thresholds at Tongogara Refugee Camp in Chipinge District during weeks 12-14. We investigated the malaria outbreak describing the outbreak by person, place and time, assessing malaria emergency preparedness and response and appropriateness of case management. We also determined the factors associated with contracting malaria to enable the formulation of appropriate interventions, establish control and prevent future malaria outbreaks among this vulnerable population.

Methods: We conducted a 1:1 unmatched case control study involving 80 cases and 80 controls using interviewer-administered questionnaires at household level. Data was entered using Epi Data version 3.1 and analyzed using Epi InfoTM version 7.2.4 to generate medians, proportions, odds ratios and their $95 \%$ confidence intervals.

Results: Malaria cases were distributed throughout the 10 residential sections within Tongogara Refugee Camp, the majority being from section $7,28 / 80$ (35\%). Despite constituting $11 \%$ of the total population, Mozambican nationals accounted for $36 / 80$ (45\%) cases. Males constituted 47/80 (59\%) among cases versus controls $43 / 80$ (54\%), $p=0.524$. Median age for cases was also lower compared to controls; 15 years [Interquartile range (IQR), 9-26] versus 17 years (IQR, 10-30). Several natural and manmade potential vector breeding sites were observed around the camp. Risk factors associated with contracting malaria were engaging in outdoor activities at night [AOR $4.26(95 \% \mathrm{Cl}, 1.43-12.68)]$, wearing clothes that do not cover the whole body $[A O R=2.74(95 \% \mathrm{Cl} 1.04-7.22)$ while sleeping in a refugee housing unit reduced the risk of contracting malaria $[\mathrm{AOR}=0.18(\mathrm{Cl}, 0.06-0.55)]$.

Conclusions: The malaria outbreak at Tongogara Refugee Camp reemphasizes the role of behavioral factors in malaria transmission. We recommend intensified health education to address human behaviors that expose residents to malaria and habitat modification with larviciding to eliminate mosquito breeding sites.

\section{Background}

Malaria is a life-threatening disease which is preventable and curable. Globally, an estimated 229 million cases of malaria and 409000 attributable deaths were reported in 2019 (1). Over the years, data has showed that the World Health Organization (WHO) African Region carries a disproportionately high share of the global malaria burden accounting for $94 \%$ of malaria cases and deaths (2). In Zimbabwe, approximately 310,000 malaria cases were reported in 2019 , translating to an incidence rate of 22 cases per 1,000 population and a total of 266 deaths (3) 
The United Nations Refugee Agency estimates that for the year 2020, there were 79.5 million forcibly displaced people, including 26 million refugees globally (4). Additionally, malaria is a leading cause of morbidity and mortality among these vulnerable populations, approximately two-thirds (63\%) of whom reside in malaria endemic regions $(4,5)$. Data on malaria incidence and mortality from the United Nations High Commissioner for Refugees (UNHCR) Health Information System (2006-2009) was analyzed by Anderson et al, 2011. The findings showed that an annual average of 111,571 malaria cases were reported among refugees and children younger than five years of age accounted for $40,410(36.2 \%)$ cases (6). Furthermore, an estimated $12.3 \%$ of all refugee deaths and $16 \%$ of deaths among refugee children under five years of age; were due to malaria (6).

Malaria is an acute febrile illness and symptoms usually appear 10-15 days after the infective mosquito bite, in a non-immune individual. In malaria endemic areas, people may develop partial immunity, allowing asymptomatic infections to occur. However, some population groups are at considerably higher risk of contracting malaria, and developing severe disease, than others. These include children less than 5 years of age, pregnant women and patients with HIV/AIDS, as well as non-immune migrants, mobile populations and travelers (7).

Amongst the causative agents of malaria, Plasmodium falciparum accounts for approximately $99.7 \%$ of estimated malaria cases in the WHO African Region, Zimbabwe included (1). The vector for malaria parasites is the female Anopheles mosquitoes, which bite mainly between sunset and sunrise. Malaria is transmitted in tropical and subtropical areas, where high temperatures, humidity and rainfall are critical for the reproduction and growth cycle of the Anopheles mosquitoes and malaria parasites (8). The WHO recommends two core vector control interventions, mainly the use of long-lasting insecticide treated nets (LLTNs) and indoor residual spraying (IRS) (1).

Weather forecasts by the Meteorological Service Department predicted above normal rainfall, for the 2020/21 rainy season in Zimbabwe (9). The Malaria Early Warning System (MEWS) under the Epidemiology and Disease Control department within the Ministry of Health and Child Care among other interventions embarked on the indoor residual spraying (IRS) program in October 2020. The aim of program was to ensure control and mitigation of malaria epidemics in Manicaland Province despite the heavy rains. Consequently, data from the rapid disease notification system (RDNS) weekly reports for Manicaland Province for weeks 1 - 14 showed a 75\% decline of malaria cases from 64130 in 2020 to 16 237 in 2021. Chipinge district also reported a 33\% decline of malaria cases from 7466 to 5005 during the same period. However, Tongogara Refugee Camp Clinic in Chipinge District reported a $123 \%$ increase in malaria cases from 75 cases in 2020 to 167 cases in 2021 between weeks $1-14$ of 2021.

Interventions implemented at Tongogara Refugee Camp to control the spread of malaria include distribution of long-lasting insecticide treated nets (LLINs), indoor residual spraying (IRS), and health information dissemination. However, the camp clinic reported 29, 20 and 23 malaria cases in week 12, 13 and 14 of 2021 respectively which are above the action threshold levels. 
Several factors promote vulnerability to malaria illness and death among refugees. Understanding the epidemiology of malaria in these vulnerable populations is important to enable the formulation of appropriate interventions to establish control and prevent future episodes of malaria outbreaks within the camp and other areas affected by humanitarian emergencies among displaced populations.

We investigated the malaria outbreak among residents at Tongogara Refugee Camp in Chipinge District, Zimbabwe, 2021. The specific objectives were to describe the outbreak by person, place and time, determine factors associated with contracting Malaria at Tongogara Refugee Camp and assess appropriateness of case management during the malaria outbreak. Additionally, we assessed malaria emergency preparedness and response as well as the knowledge of malaria among the refugees.

\section{Methods}

\section{Study design and setting}

We conducted an unmatched 1:1 case-control study at Tongogara Refugee Camp which has been in existence since 1983 and was established by the Government of Zimbabwe as a result of civil unrest in neighboring Mozambique. The open community camp originally designed to cater for a maximum of 3,000 people has an estimated 15,049 refugees within 10 housing sections and over 200 Zimbabwean nationals working for various organizations as at 30 April 2021.

Males constitute $7999 / 15049$ (53.2\%) of the total population while children aged 5-9 years account for the majority of the population $2375 / 15049$ (15.8\%) followed by children under 5 years constituting $2125 / 15049(14.1 \%)$. However, the population is not static as there are new refugee arrivals and departures almost on a daily basis. To date, more than three quarters of the population originates from the Democratic Republic of Congo followed by nationals from Mozambique 1644/15049 (11\%), Burundi 918/15049 (6\%) and Rwanda 689/15049 (5\%). The Refugee Camp has an Early Child Development (ECD) Centre, Tongogara Primary, St Michael's Secondary School and a vocational training center. Tongogara Refugee Camp Clinic is the only health facility within the camp and provides all basic primary care services free of charge.

The camp area falls under the agro-ecological zone five that normally experiences low amount of rainfall, on average 200 to $400 \mathrm{~mm}$ per year. The refugee camp is bordered by Save River and Save Wildlife Conservancy. While the camp has electricity at the clinic, for lighting and cooking refugees are largely provided with solar lamps and firewood. The camp is characterized by gravel roads and access is difficult during the rainy season. Refugees at Tongogara survive on food assistance from the World Food Program (WFP) and engage in horticulture, fishing and livestock farming. Several tuck-shops have also been established within the camp. The UNHCR is the leading non-governmental organisation (NGO) providing humanitarian assistance and partners with other organisations including Terre des homes (TDH), World Vision and the Jesuit Refugee Service.

\section{Study population}


Our study population included any individual residing within Tongogara Refugee Camp and was willing to participate in the study. Children under 12 years of age were interviewed with the assistance of their care givers. We excluded any individual who was not in the refugee camp during the outbreak period. Individuals who had symptoms suggestive of malaria but had no laboratory confirmation were also excluded from the study. We calculated a minimum sample size of 80 cases and 80 controls using Fleiss formula at $95 \%$ confidence interval and $80 \%$ power based on a study by Chirebvu et al in northern Botswana, 2014 where those engaging in late night activities where 7.06 times more likely to contract malaria (10).

\section{Sampling technique}

We included all confirmed cases from the 22nd of March 2021 to the 18th of April 2021. We created a line-list using the T12 and Integrated management of childhood illnesses (IMCI) registers at Tongogara Refugee Camp Clinic. The sampling frame for controls was the $\mathrm{T} 12$ and IMCI registers and included patients with a negative malaria rapid diagnostic test. Systematic random sampling of controls involved determining the sampling interval by dividing the number of people on the line-list by the required sample size of 80 controls. The first control was randomly selected after which a sampling interval of 3 was used to select the remaining controls until the sample size was reached.

\section{Data collection methods}

Interviewer-administered questionnaires at household level were used to collect information on demographic and behavioral characteristics, risk factors for contracting malaria, knowledge of malaria and practices among cases and controls. Three community health promoters working within the camp assisted with language translation during the interviews between English and other languages common among respondents (i.e. Swahili, French, Shona and Portuguese). The questionnaire was pre-tested prior to data collection. A key informant guide was used to elicit information on malaria outbreak preparedness and response. Key informants interviewed at Tongogara Refugee Camp Clinic included the sister-in-charge, three nurses, one environmental health technician (EHT), one pharmacy technician, four community health promoters (village health workers) and the District Environmental Health Officer (DEHO).

We reviewed health records to assess how cases were managed by going through outpatient cards and clinic records. Observations were done as interviews were being conducted, with consent from the participants to check on whether the LLINs were available and hanged appropriately. The surrounding environment was assessed by checking for larval habitats close to the homes and this was done by the naked eye. The anopheles mosquito larvae characteristically rest parallel to and just below the water surface. A camera was used to take pictures of known environmental elements that facilitate breeding of anopheles mosquitoes in the camp site such as stagnant water bodies, water filled pits, and swamps. We assessed the availability of resources, outbreak preparedness and response using a customized checklist. 


\section{Data analysis}

We used Epi Data version 3.1 for data entry and Epi Info ${ }^{\mathrm{TM}}$ version 7.2.4 for analysis to generate medians, frequencies, proportions, odds ratios and their corresponding $95 \%$ confidence intervals. Forward step-wise logistic regression analysis was done to determine the independent factors associated with contracting malaria. All variables that were associated with contracting malaria with a $p$-value $\leq 0.25$ were included in the logistic regression model. For all the tests conducted, $p<0.05$ indicates statistical significance. Qualitative data from key informants was analyzed thematically, based on responses to specific questions. We assessed malaria knowledge levels among study participants using a 3-point Likert scale where those who scored zero to two questions correctly had poor knowledge, those who scored three had fair knowledge and those who scored four to five had good knowledge.

\section{Results}

We interviewed 80 cases and 80 controls and there were no deaths recorded. The majority of study participants were males $47 / 80(59 \%)$ of cases and $43 / 80(54 \%)$ of controls ( $p=0.524)$. The median age for cases was 15 years and half were aged between $9-26$ years while among the controls it was 17 years and half were aged between 10-30 years. The majority of cases were from Mozambique $36 / 80(45 \%)$ followed by the Democratic Republic of Congo 29/80(36\%). No participants had been resident in the camp for $<6$ months with $57 / 80(71 \%)$ cases and $56 / 80(70 \%)$ controls having been resident in the camp for a period of $<5$ years $(p=0.233)$. About $45 / 80(56 \%)$ cases and $30 / 80(37 \%)$ controls had only attained primary education $(p=0.017)$. Most cases $61 / 80(76 \%)$ and controls $52 / 80(65 \%)$ were not involved in any income generating activities $(p=0.295)$. Table 1 summarises the socio demographic characteristics of study participants at Tongogara Refugee Camp. 
Table 1

Socio-demographic characteristics of study participants at Tongogara Refugee Camp, Chipinge District, Zimbabwe, 2021

\begin{tabular}{|c|c|c|c|c|c|c|}
\hline \multirow[t]{2}{*}{ Variable } & \multirow[t]{2}{*}{ Category } & \multicolumn{2}{|l|}{ Cases } & \multicolumn{2}{|c|}{ Controls } & \multirow{2}{*}{$\begin{array}{l}\mathrm{p}- \\
\text { value }\end{array}$} \\
\hline & & $\mathrm{n}=80$ & Percent & $n=80$ & Percent & \\
\hline \multirow[t]{2}{*}{ Sex } & Male & 47 & 59 & 43 & 54 & 0.524 \\
\hline & Female & 33 & 41 & 37 & 46 & \\
\hline \multirow[t]{5}{*}{ Age (Years) } & $\leq 5$ years & 12 & 15 & 10 & 12 & 0.693 \\
\hline & $>5$ years & 67 & 84 & 67 & 84 & \\
\hline & $\begin{array}{l}\text { Age not } \\
\text { known }\end{array}$ & 1 & 1 & 3 & 4 & \\
\hline & & \multicolumn{2}{|c|}{$\begin{array}{l}\text { Median age }= \\
15\end{array}$} & \multicolumn{2}{|c|}{$\begin{array}{l}\text { Median age }= \\
17\end{array}$} & 0.755 \\
\hline & & \multicolumn{2}{|c|}{$Q_{1}=9 ; Q_{3}=26$} & \multicolumn{2}{|c|}{$Q_{1}=10 ; Q_{3}=30$} & \\
\hline \multirow[t]{6}{*}{ Country of origin } & Mozambique & 36 & 45 & 36 & 45 & 0.97 \\
\hline & DRC & 29 & 36 & 27 & 34 & \\
\hline & Zimbabwe & 6 & 8 & 5 & 6 & \\
\hline & Burundi & 4 & 5 & 5 & 6 & \\
\hline & Rwanda & 3 & 4 & 3 & 4 & \\
\hline & Other & 2 & 2 & 4 & 5 & \\
\hline \multirow[t]{2}{*}{ Pregnancy status } & No & 31 & 97 & 32 & 91 & 0.615 \\
\hline & Yes & 1 & 3 & 3 & 9 & \\
\hline \multirow[t]{4}{*}{ Level of Education } & None & 19 & 24 & 23 & 29 & 0.017 \\
\hline & Primary & 45 & 56 & 30 & 37 & \\
\hline & Secondary & 9 & 11 & 23 & 29 & \\
\hline & Tertiary & 7 & 9 & 4 & 5 & \\
\hline \multirow[t]{4}{*}{ Occupation } & None & 61 & 76 & 52 & 65 & 0.295 \\
\hline & Farming & 9 & 11 & 13 & 16 & \\
\hline & $\begin{array}{l}\text { Shop } \\
\text { attendant }\end{array}$ & 4 & 5 & 2 & 3 & \\
\hline & Other & 6 & 8 & 13 & 16 & \\
\hline
\end{tabular}




\begin{tabular}{|lllllll|}
\hline Variable & Category & Cases & Controls & $\begin{array}{l}\text { p- } \\
\text { value }\end{array}$ \\
\hline $\begin{array}{l}\text { Period of residence in the camp } \\
\text { (Years) }\end{array}$ & $2-5$ & 57 & 71 & 56 & 70 & 0.233 \\
\hline & $6-10$ & 10 & 13 & 11 & 13 & \\
\hline & $11-15$ & 8 & 10 & 9 & 11 & \\
\hline & $16-20$ & 5 & 6 & 5 & 6 & \\
\hline
\end{tabular}

The majority of cases $70 / 80(87 \%)$ and controls $65 / 80(81 \%)$, resided within $3 \mathrm{~km}$ of a stagnant water body $(P=0.276)$. Natural vector breeding sites observed included a swampy area in section 10 and marshes in section 7 referred to as Mayeze Dam. Vector breeding sites from human activities included water from the communal taps collecting in ditches, an irrigation scheme within the camp as well as pits created by residents as water reservoirs for gardening. Waste from the piggery project also provided potential vector breeding sites. We observed poor waste management practices as there were plastic containers and litter around the camp and in the stagnant water bodies. Key informants highlighted that there was poor drainage in the camp.

Majority of cases $67 / 80(84 \%)$ and $68 / 80(85 \%)$ controls did not have a mosquito net and mentioned that nets which had been distributed to them more than three years prior to the study were torn $(p=0.043)$. About $42 / 80(53 \%)$ controls resided in refugee housing units while $41 / 80(51 \%)$ of cases lived in houses constructed with bricks and iron roof sheets $(\mathrm{p}<0.001)$. Indoor residual spraying using primiphos methyl had been conducted in the last 12 months for $68 / 80(85 \%)$ cases and $70 / 80(88 \%)$ controls $(p=0.646)$. Forty families arrived after IRS was done and these are not protected and nothing was done to them in terms of malaria intervention. The majority of cases $48 / 80(60 \%)$ engaged in outdoor activities at night compared to $23 / 80(29 \%)$ controls $(\mathrm{p}<0.001)$. Most commonly mentioned outdoor activities included socializing with friends and family, playing and cooking. Based on self-reported travel $71 / 80(89 \%)$ cases and $77 / 80(96 \%)$ controls self-reported had not travelled outside the camp in the last month $(p=0.086)$ (Table 2). 
Table 2

Household and behavioral characteristics of study participants at Tongogara Refugee Camp, Chipinge District, Zimbabwe, 2021

\begin{tabular}{|c|c|c|c|c|c|c|}
\hline \multirow[t]{2}{*}{ Variable } & \multirow[t]{2}{*}{ Category } & \multicolumn{2}{|l|}{ Cases } & \multicolumn{2}{|c|}{ Controls } & \multirow{2}{*}{$\begin{array}{l}\mathrm{P}- \\
\text { value }\end{array}$} \\
\hline & & $\mathrm{n}=80$ & Percent & $\mathrm{n}=80$ & Percent & \\
\hline \multirow{2}{*}{$\begin{array}{l}\text { Presence of a stagnant water body } \\
3 \mathrm{~km} \text { from the home }\end{array}$} & Yes & 70 & 87 & 65 & 81 & 0.276 \\
\hline & No & 10 & 13 & 15 & 19 & \\
\hline \multirow{2}{*}{$\begin{array}{l}\text { Slept under a mosquito net the } \\
\text { previous night }\end{array}$} & Yes & 10 & 12 & 11 & 14 & 0.815 \\
\hline & No & 70 & 88 & 69 & 86 & \\
\hline \multirow{2}{*}{$\begin{array}{l}\text { Ownership of a mosquito net in } \\
\text { the last } 6 \text { months }\end{array}$} & Yes & 13 & 16 & 12 & 15 & 0.087 \\
\hline & No & 67 & 84 & 68 & 85 & \\
\hline \multirow[t]{4}{*}{ Type of house } & $\begin{array}{l}\text { Brick under } \\
\text { iron }\end{array}$ & 41 & 51 & 34 & 42 & $<0.001$ \\
\hline & $\begin{array}{l}\text { Brick under } \\
\text { asbestos }\end{array}$ & 18 & 22 & 4 & 5 & \\
\hline & $\begin{array}{l}\text { Refugee } \\
\text { housing unit }\end{array}$ & 14 & 18 & 42 & 53 & \\
\hline & $\begin{array}{l}\text { Mud under } \\
\text { thatch }\end{array}$ & 7 & 9 & 0 & 0 & \\
\hline \multirow[t]{2}{*}{ Holes or open eaves in the house } & Yes & 26 & 33 & 10 & 12 & 0.002 \\
\hline & No & 54 & 67 & 70 & 88 & \\
\hline \multirow[t]{2}{*}{ IRS in the last 12 months } & Yes & 68 & 85 & 70 & 88 & 0.646 \\
\hline & No & 12 & 15 & 10 & 12 & \\
\hline \multirow[t]{2}{*}{ Outdoor activities at night } & Yes & 48 & 60 & 23 & 29 & $<0.001$ \\
\hline & No & 32 & 40 & 57 & 71 & \\
\hline \multirow{2}{*}{$\begin{array}{l}\text { Wearing clothes that cover during } \\
\text { outdoor activities }\end{array}$} & Yes & 26 & 32 & 56 & 70 & $<0.001$ \\
\hline & No & 54 & 68 & 24 & 30 & \\
\hline \multirow[t]{2}{*}{ Use of mosquito repellents } & Yes & 10 & 13 & 3 & 4 & 0.043 \\
\hline & No & 70 & 87 & 77 & 96 & \\
\hline \multirow{2}{*}{$\begin{array}{l}\text { Travel outside the camp (self- } \\
\text { reported) }\end{array}$} & Yes & 3 & 4 & 9 & 11 & 0.086 \\
\hline & No & 77 & 96 & 71 & 89 & \\
\hline Malaria education in the last 3 & Yes & 9 & 11 & 13 & 16 & 0.463 \\
\hline
\end{tabular}




\begin{tabular}{|lllllll|}
\hline Vanthable & Category & Cases & Controls & $\begin{array}{c}\text { P- } \\
\text { value }\end{array}$ \\
\hline No & 71 & 89 & 67 & 84 & \\
\hline
\end{tabular}

Tongogara Refugee Camp Clinic recorded an increase in malaria cases above the alert and action threshold limits in week 12 of 2021 reaching a peak of 29 cases by the end of week 12 . Thereafter, the cases declined steadily. The decline in the number of malaria cases in week 17 also coincided with the start of the winter season by the end of the month of April. The epicurve for malaria cases at Tongogara Refugee Camp, Chipinge District, Zimbabwe 2021 is based on the date of diagnosis (Figure 1).

Malaria cases were distributed throughout the 10 residential sections within Tongogara Refugee Camp, however, the majority of cases 28/80(35\%) came from section 7 followed by section $613 / 80$ (16\%) and Section 9 11/80 (14\%). Marshes (Mayeza Dam) in section 7 and a swampy area section 10 were in the camp. Stagnant water bodies were a common feature around the camp. A bridge was constructed between section 1 and 2 near Tongogara Refugee Camp Clinic and stagnant water could be seen on both sides of the bridge. Figure 2 illustrates the spot map showing the distribution of malaria cases in Tongogara Refugee Camp during the outbreak.

\section{Malaria case management at Tongogara Refugee Camp Clinic, Chipinge District, 2021}

All cases were diagnosed at the clinic using the First Response Malaria Antigen ( $\mathrm{pLDH} / \mathrm{HRP}_{2}$ ) Combo rapid diagnostic test (RDT) following Ministry of Health standardized protocols. Cases presenting with mild symptoms were $43 / 80(54 \%)$ while $33 / 80(41 \%)$ had moderate symptoms and $4 / 80(5 \%)$ presented with severe symptoms. The majority of cases $64 / 80(80 \%)$ presented with a fever followed by a headache and chills constituting $52 / 80(65 \%)$ and $30 / 80(38 \%)$ respectively. There were no complicated malaria cases and all cases were treated with co-artermether at the clinic. No malaria deaths were reported at Tongogara Refugee Camp. The majority of cases 78/80(97\%) had completed their course while 2/80 (3\%) had stopped taking their medication when the symptoms subsided.

\section{Outbreak emergency preparedness and response at Tongogara Refugee Camp Clinic}

Tongogara Refugee Camp Clinic has four nurses, one environmental health technician, one pharmacy technician and one nurse aide. An assessment of the outbreak emergency preparedness and response showed that five out of seven health workers had received previous training on malaria case management. Two out of five health workers received training on integrated disease surveillance and response (IDSR).

The emergency preparedness and response committee comprising of the camp administrator, camp coordinator, nurse, environmental health technician and a World Vision representative meets once every month. An emergency preparedness and response plan was available at Tongogara Refugee Camp Clinic. 
The malaria case management guidelines and weekly malaria threshold limits were up to date and displayed on the walls, however, there was no spot map or line list at the clinic. The malaria outbreak was detected 7 days after the onset of the outbreak and the clinic notified the outbreak to the district within the same period. However, the rapid response team initiated an outbreak investigation after 3 weeks. The district rapid response team investigated the outbreak 2 months after the outbreak had occurred. Longlasting insecticide treated nets (LLINs) were distributed to pregnant women. The IRS coverage for Tongogara Refugee Camp was $85 \%$ compared to the program reported coverage of $94 \%$. No larviciding was conducted at the Tongogara Refugee Camp. Table 3 shows the malaria outbreak emergency preparedness and response at Tongogara Refugee Camp Clinic. 
Table 3

Malaria outbreak emergency preparedness and response at Tongogara Refugee Camp, Chipinge District, Zimbabwe, 2021

\begin{tabular}{|c|c|c|}
\hline Activity & Target & Achieved \\
\hline \multicolumn{3}{|l|}{$\begin{array}{l}\text { Number of health workers } \\
\text { trained }\end{array}$} \\
\hline $\begin{array}{l}\text { Integrated disease } \\
\text { surveillance and response }\end{array}$ & 5 & 2 \\
\hline Malaria case management & 7 & 5 \\
\hline \multicolumn{3}{|l|}{ Emergency preparedness } \\
\hline $\begin{array}{l}\text { Availability of standard } \\
\text { treatment protocols for } \\
\text { malaria }\end{array}$ & Available & Available \\
\hline Rapid Response Team & $\begin{array}{l}1 \text { team } \\
\text { available }\end{array}$ & 1 team available \\
\hline EPR plan & Available & Available \\
\hline \multicolumn{3}{|l|}{$\begin{array}{l}\text { Outbreak detection and } \\
\text { notification }\end{array}$} \\
\hline $\begin{array}{l}\text { Outbreak detection, } \\
\text { notification and response }\end{array}$ & $\begin{array}{l}\text { Within } \\
48 \text { hours }\end{array}$ & $\begin{array}{l}\text { Untimely: Outbreak was detected after } 7 \text { days and } \\
\text { notified after } 14 \text { days }\end{array}$ \\
\hline Initiation of investigation & $\begin{array}{l}\text { Within } \\
48 \text { hours }\end{array}$ & $\begin{array}{l}\text { Untimely, the rapid response team initiated the } \\
\text { investigation } 3 \text { weeks after the outbreak was detected }\end{array}$ \\
\hline Line list & Available & Not available \\
\hline Spot map & Available & Not available \\
\hline \multicolumn{3}{|l|}{ Outbreak control } \\
\hline Outbreak control & 14 days & The outbreak persisted for 28 days \\
\hline $\begin{array}{l}\text { Community sensitization and } \\
\text { health education }\end{array}$ & Done & Done \\
\hline $\begin{array}{l}\text { Distribution of mosquito nets } \\
\text { in the last } 6 \text { months }\end{array}$ & $85 \%$ & $2 \%$ \\
\hline IRS (Population coverage) & $95 \%$ & $85 \%$ \\
\hline $\begin{array}{l}\text { Insecticide efficacy testing in } \\
\text { the last } 6 \text { months }\end{array}$ & Done & Not done \\
\hline Larviciding & $95 \%$ & $0 \%$ \\
\hline
\end{tabular}

\section{Entomological surveillance activities conducted in Tongogara Refugee Camp}


Entomological surveillance activities conducted at the refugee camp involved larval sampling and pyrethrum spray catches to determine the indoor vector density and distribution. Pyrethrum spray catches (PSCs) conducted in November 2020 in section 7 and section 10 of the camp before the IRS exercise (preIRS PSCs) captured eight Anopheles gambiae mosquitoes and 66 culicines. However, post-IRS PSCs did not capture any vectors. No further evaluations for vector density comparison were done due to limited supply of aerosol to use. To further investigate the outbreak PSCs were performed in section 7 in June 2021 and did not yield any indoor resting mosquitoes, however larval sampling conducted in response to the outbreak at Mayeza Dam in section 7 harvested 18 anopheles' larvae.

Factors associated with contracting malaria at Tongogara Refugee Camp, Chipinge District, Zimbabwe, 2021

The odds of contracting malaria were 3.72 times higher for those engaging in outdoor activities at night when compared to those who did not [OR=3.72 $(95 \% \mathrm{Cl}, 1.92-7.19)]$. The odds of contracting malaria were 4.76 times higher for those who did not wear clothes that covered their whole body while engaging in outdoor activities at night when compared to those who wore clothes that covered the whole body [OR=4.76 $(95 \% \mathrm{Cl}, 2.43-9.30)]$.The odds of contracting malaria when residing in a refugee housing unit were $72 \%$ lower compared to participants residing in a house with brick under iron and was considered protective [OR $=0.28(95 \% \mathrm{Cl}, 1.15-12.08)]$. Table 4 shows the factors associated with contracting malaria at Tongogara Refugee Camp, Chipinge District, Zimbabwe, 2021 
Table 4

Factors associated with contracting malaria at Tongogara Refugee Camp, Chipinge District, Zimbabwe, 2021

\begin{tabular}{|c|c|c|c|c|c|c|}
\hline \multirow[t]{2}{*}{ Variable } & \multicolumn{2}{|c|}{ Cases } & Controls & OR & $(95 \% \mathrm{Cl})$ & $\begin{array}{l}\text { P- } \\
\text { value }\end{array}$ \\
\hline & $\begin{array}{l}n \\
=80\end{array}$ & Percent & $\begin{array}{l}n \\
=80\end{array}$ & & & \\
\hline
\end{tabular}

No. of children $\geq 5$ yrs in household

$\begin{array}{llllllll}0 & 67 & 84 & 53 & 67 & \text { Reference } & & \\ 1 & 7 & 9 & 10 & 7 & 0.55 & 0.20-1.55 & 0.261 \\ 2+ & 6 & 7 & 17 & 6 & 0.28 & 0.10-0.76 & 0.012\end{array}$

\section{Type of house}

\begin{tabular}{lccccccc} 
Brick under iron & 41 & 51 & 34 & 42 & Reference & \\
$\begin{array}{l}\text { Pole/mud under } \\
\text { thatch }\end{array}$ & 7 & 9 & 0 & 0 & - & - & - \\
\hline Refugee housing unit & 14 & 18 & 42 & 53 & 0.28 & $(0.13-0.59)$ & 0.001 \\
\hline Brick under asbestos & 18 & 22 & 4 & 5 & 3.73 & $\begin{array}{l}(1.15- \\
12.08)\end{array}$ & 0.028 \\
\hline
\end{tabular}

Holes or open eaves in the house

\begin{tabular}{|llllllll|}
\hline No & 54 & 68 & 70 & 88 & Reference & & \\
\hline Yes & 26 & 31 & 10 & 12 & 3.37 & $(1.5-7.58)$ & 0.003 \\
\hline
\end{tabular}

\section{Outdoor activities at night}

\begin{tabular}{|llllllll|}
\hline No & 32 & 40 & 57 & 71 & Reference & & \\
\hline Yes & 48 & 60 & 23 & 29 & 3.72 & $(1.92-7.19)$ & $<0.001$
\end{tabular}

Wear clothes that cover the body during outdoor activities at night

\begin{tabular}{|llllllll|}
\hline Yes & 26 & 32 & 56 & 70 & Reference & \\
\hline No & 54 & 68 & 24 & 30 & 4.76 & $(2.43-9.3)$ & $<0.001$ \\
\hline
\end{tabular}

\section{Independent risk factors associated with having malaria in Tongogara Refugee Camp, 2021}

The independent risk factors associated with contracting malaria among study participants at Tongogara Refugee Camp were engaging in outdoor activities at night [AOR $4.26(95 \% \mathrm{Cl}, 1.43-12.68)$ ] and wearing clothes that do not cover the whole body [AOR=2.74 (95\% Cl 1.04-7.22) while sleeping in a refugee housing unit $(\mathrm{RHU})$ reduced the risk of contracting malaria by $82 \%[\mathrm{AOR}=0.18(\mathrm{Cl}, 0.06-0.55)]$. 


\section{Malaria knowledge among study participants at Tongogara Refugee Camp, Zimbabwe, 2021}

Amongst the study participants, $58 / 80(71 \%)$ knew how malaria was transmitted compared to $74 / 80$ (91\%) controls and 50/80 (63\%) cases knew that malaria was common during the rainy season compared to $71 / 80(89 \%)$ controls. Sleeping under a mosquito net was the most commonly mentioned protective measure suggested by $59 / 80(74 \%)$ cases and $67 / 80$ (84\%) controls, however, only $18 / 80$ $(23 \%)$ cases $21 / 80(26 \%)$ controls mentioned IRS as one of the malaria preventive measures. Overall, $37 / 80(46 \%)$ cases had poor knowledge on malaria while $32 / 80(40 \%)$ of controls had good knowledge $(p=0.04)$.

\section{Discussion}

The majority of cases resided in section 7 and had been resident in Tongogara Refugee Camp for $2-5$ years. Section 7 is predominantly occupied by Mozambican nationals. Despite constituting only $11 \%$ of the total population, nationals from Mozambique accounted for almost half of malaria cases. Muyeze Dam in section 7 from which mosquito larvae were harvested suggests that the dam was the major environmental source of the mosquito vectors compared to all the other sections within the camp thus accounting for the higher number of cases. However, entomological surveillance activities were conducted during the winter season in June when temperatures were low and some of the larval habitats had dried up interrupting the anopheles mosquito lifecycle. Tongogara Refugee Camp is bordered by Save River on the West. Additionally, heavy rains received between January and March of 2021 resulted in the creation of stagnant water bodies in ditches and marshes in the camp. Coupled with poor waste management, these potential malaria vector breeding sites may have resulted in increased vector density. This is consistent with findings by Workineh et al, 2019 who found that the presence of rivers, stagnant water and poor environmental controls were associated with occurrence of malaria outbreaks (11). Poor drainage in the camp exacerbates the development of stagnant water bodies. The Roll Back Malaria Vector Control Working Group report of 2017 found that soil with poor drainage enabled larval habitats for Anopheles Arabiensis mosquitoes at Doro refugee camp in South Sudan (12). Resources to facilitate the use of drone technology to carry out hydrological mapping for improved drainage in the camp are limited.

Human activities involving agricultural activities, water from communal taps collecting in ditches and poor waste management practices also resulted in potential vector breeding sites. This is consistent with findings by Bayoh et al, 2011 who observed larval habitats from man-made pits of water associated with tap stands installed for water delivery to residents in the camp (13).

Tongogara Refugee Camp achieved an optimal IRS coverage which meets the WHO recommended impact level of $85 \%$ but failed to reach the national target of $95 \%$. Compared to the rest of Chipinge District which uses the organochlorine insecticide (DDT), broad spectrum insecticides such as organophosphates (pirimiphos methly) or pyrethroids are used for IRS in Tongogara Refugee Camp. 
Organochlorine insecticide has a slow knockdown effect on mosquitoes but long efficacy of 9-12 months while organophosphates have a fast knockdown effect on mosquitoes and other insects including fleas, lice, cockroaches and termites. This increased acceptability of IRS among refugees consistent with Messanger et al, 2020 who found that other benefits of vector control interventions, such as reducing flies in households and nuisance biting may make IRS interventions more acceptable to the user (4).

The last IRS exercise at Tongogara Refugee Camp was carried out in November using pirimiphos methly, hence for those rooms that had been sprayed, the insecticide was effective. This is based on a study by Chanda et al, 2013 who showed that the residual efficacy of pirimiphos methyl lasted for 5 months on both cement and mud walls (14). To avoid insecticide resistance, the Zimbabwe 2016-2020 National Malaria Strategic Plan, recommends the rotation of insecticides after two years of use and the use of insecticides with different modes of action taking into consideration the available vector resistance data (18). No larviciding was conducted at the vector breeding sites. The WHO recommends larviciding in areas where mosquito breeding sites are few, fixed and findable, as is the case at Tongogara Refugee Camp (15).

The independent risk factors associated with contracting malaria among study participants at Tongogara Refugee Camp were engaging in outdoor activities at night and wearing clothes that did not cover the whole body during outdoor activities. Engaging in outdoor activities such as socializing and cooking amongst the adults and playing is common practice in the camp and some participants indicated that they would sleep outside their homes during the hot summer nights. Engaging in outdoor activities exposes one to mosquito bites and reduces the use of indoor residual spraying. This is consistent with findings by Mugwagwa et al who found that outdoor activities before dawn and after dusk were significant risk factors for contracting malaria, while wearing clothes that cover the whole body was protective (16). The use of insecticide treated nets and indoor residual spraying was reduced during the hot season when the population sleeps outside (12). On the other hand, sleeping in a refugee housing unit (RHU) was found to decrease the risk of contracting malaria as it offered protection from insects.by having the windows that are covered by breathable material. The RHU design provides the recommended minimum living space for a small family, however it has an average lifespan of 3 years (17).

The majority of study participants did not own a mosquito net and refugees who had received a net 3 years prior to the study reported that the nets were torn. Long lasting insecticide treated nets are designed to retain their efficacy against mosquito vectors for a minimum of 3 years or 20 standard washes under laboratory conditions $(18,19)$. WHO recommends the provision, use and timely replacement of longlasting insecticidal nets or, where appropriate, the application of indoor residual spraying. However one core intervention should not be introduced as a means of compensating for deficiencies in the implementation of the other (20). The Zimbabwe 2016-2020 National Malaria Strategic Plan, deploys IRS in areas with an annual parasite index (API) of 5 per 1,000 population or greater such as Chipinge District while LLINs are deployed in areas with an API of 2 - 4 per 1,000 population (21). The distribution of nets for outdoor sleeping spaces among populations that are prone to sleeping outside during summer is 
recommended according to the Zimbabwe National Malaria Programme (21). Insecticide-treated nets are only effective if used consistently (22).

Despite the outbreak being detected after 48 hours, Tongogara Refugee Camp Clinic was well prepared to respond to the outbreak. The outbreak investigation was delayed due to limited human resources as there is 1 resident environmental health technician who is not replaced when off duty. The response to the outbreak by the district was not timely as surveillance activities were conducted during the winter season when vector density had declined. This is consistent with findings by Muchena et al, 2014 who concluded that poor outbreak response may have propagated the malaria outbreak (23)

The majority of cases had poor knowledge of malaria while the majority of controls had fair knowledge. This is consistent with findings by Kureya et al, 2017 who found that having poor knowledge predisposed people to contracting malaria (24). Addressing community knowledge gaps through campaigns particularly before the onset of the malaria season may facilitate successful implementation of malaria prevention measures.

\section{Limitations}

The limitations of our study were that it involved the use of local community health promoters as interpreters. Although the interview questions were first piloted in the non-English speaking participants' languages mainly Swahili, French, Shona and Portuguese, we had to rely on the interpreter to keep the questions non-leading and neutral and to prompt the participants for further clarification in some instances. Using the community health promoters who were already known by the community compromised confidentiality as there was a third party listening to the interview. Recall bias may be a limitation in our study as participants were responding to questions about the past. We could not ascertain if any malaria cases were imported from Mozambique.

\section{Conclusion}

The malaria outbreak at Tongogara Refugee Camp reemphasizes the role of behavioral factors in malaria transmission. Independent risk factors associated with contracting malaria were engaging in outdoor activities at night and wearing clothes that do not cover the whole body during outdoor activities at night. The outbreak response was delayed due to limited human resources as there is 1 resident environmental health technician who is not replaced when off duty. We also recommended indoor residual spraying with a broad spectrum insecticide twice a year to ensure vector control in the households and elimination of other disease causing insects. Health education may be intensified to address human behaviors that expose one to malaria as well as the distribution of mosquito repellents. We also recommend larviciding of existing vector breeding sites. Health education was given to study participants at the end of each interview so as to demystify myths and correct misconceptions on malaria transmission, prevention and control. 


\section{List Of Abbreviations}

UNHCR - United Nations High Commissioner for Refugees; LLTNs - Long-lasting insecticide treated nets; IRS - Indoor residual spraying; RDNS - Rapid disease notification system; EHT - Environmental health technician; DEHO - District Environmental Health Officer; IDSR - Integrated disease surveillance and response; IQR - Interquartile range; PSCs - Pyrethrum spray catches

\section{Declarations}

\section{Ethics approval and consent to participate}

Permission to conduct the study was granted from the Health Studies Office in the Ministry of Health and Child Care (MOHCC), the Manicaland Provincial Medical Director and the Chipinge District Medical Officer as well as Tongogara Refugee Camp Commissioner for Refugees. Names and addresses of participants were not used during the study; instead unique identifiers were used to de-identify study respondents. All the information concerning the study was kept in private and confidentiality was maintained. We obtained written informed consent from the respondents including parents or legal guardians and assent for those that could not legally consent. All COVID-19 safety precautions were observed throughout the data collection procedures including the observance of social distancing and use of masks and hand sanitizing.

\section{Consent for publication}

All informed written consent also included an insertion that gave consent for publication of obtained data.

\section{Availability of data and materials}

Data for this study have been included within the document. For any further information that might be required, the corresponding authors is willing to provide the information.

\section{Competing interests}

The authors declare that they have no competing interests

\section{Funding}

The study was self-funded

\section{Authors' contributions}

KPT, SN, NTG, TJ, AC, EG and MT conceived the idea for the project. SN and MT supervised the study. EG, NTG, AC and TJ helped with the identification of cases and controls for the study. KTP, SN, NTG, AC and 
MT analysed and interpreted the data. KPT wrote the first draft of the manuscript. All the authors revised the manuscript and approved the final version to be submitted.

\section{Acknowledgements}

The authors would like to thank the Tongogara Refugee Camp management as well as camp clinic staff for their valuable assistance in the identification of potential participants and availing data to make this study a success.

\section{References}

1. WHO. Fact sheet about Malaria [Internet]. 2021 [cited 2021 Apr 15]. Available from: https://www.who.int/news-room/fact-sheets/detail/malaria

2. World malaria report 2020 [Internet]. [cited 2021 Jun 17]. Available from: https://www.who.int/publications/i/item/9789240015791

3. President's Malaria Initiative | Zimbabwe | CDC Global Health [Internet]. 2020 [cited 2021 Apr 16]. Available from: https://www.cdc.gov/globalhealth/countries/zimbabwe/annual-report/pmi.html

4. Messenger LA, Furnival-Adams J, Pelloquin B, Rowland M. Vector control for malaria prevention during humanitarian emergencies: protocol for a systematic review and meta-analysis. medRxiv [Internet]. 2020 Nov 18 [cited 2021 Apr 17];2020.11.16.20232306. Available from: https://www.medrxiv.org/content/10.1101/2020.11.16.20232306v1

5. Malaria control in complex emergencies: an inter-agency field handbook / World Health Organization ... et al.] [Internet]. [cited 2021 Apr 16]. Available from: https://apps.who.int/iris/handle/10665/43383

6. Anderson J, Doocy S, Haskew C, Spiegel P, Moss WJ. The burden of malaria in post-emergency refugee sites: A retrospective study. Conflict and Health [Internet]. 2011 Sep 19 [cited 2021 Apr 16];5(1):17. Available from: https://doi.org/10.1186/1752-1505-5-17

7. World Health Organization, editor. Malaria control in humanitarian emergencies: an inter-agency field handbook. 2nd ed. Geneva, Switzerland: World Health Organization; 2013. 220 p.

8. Centers for Disease Control and Prevention (CDC). Malaria: Where Malaria Occurs [Internet]. 2020 [cited 2021 Apr 16]. Available from: https://www.cdc.gov/malaria/about/distribution.html

9. Meteorological Services Department of Zimbabwe National Climate Outlook Forum [Internet]. [cited 2021 Jun 16]. Available from: http://www.cfuzim.com/wp-content/uploads/2020/09/msd2021.pdf

10. Chirebvu E, Chimbari MJ, Ngwenya BN. Assessment of Risk Factors Associated with Malaria Transmission in Tubu Village, Northern Botswana. Malar Res Treat [Internet]. 2014 [cited 2021 Aug 16];2014:403069. Available from: https://www.ncbi.nlm.nih.gov/pmc/articles/PMC3976786/

11. Workineh B, Mekonnen FA, Sisay M, Gonete KA. Malaria outbreak investigation and contracting factors in Simada District, Northwest Ethiopia: a case-control study | BMC Research Notes | Full Text [Internet]. [cited 2021 Apr 17]. Available from:

https://bmcresnotes.biomedcentral.com/articles/10.1186/s13104-019-4315-z 
12. Vector-Control-Humanitarian-Emergency-meeting-report-.pdf [Internet]. [cited 2021 Apr 17]. Available from: https://endmalaria.org/sites/default/files/Vector-Control-Humanitarian-Emergency-meetingreport-.pdf

13. Nabie Bayoh M, Akhwale W, Ombok M, Sang D, Engoki SC, Koros D, et al. Malaria in Kakuma refugee camp, Turkana, Kenya: facilitation of Anopheles arabiensis vector populations by installed water distribution and catchment systems. Malaria Journal [Internet]. 2011 Jun 4 [cited 2021 Apr 16];10(1):149. Available from: https://doi.org/10.1186/1475-2875-10-149

14. Emmanuel Chanda, Javan Chanda, Alister Kandyata, Faustina N Phiri, Lucy Muzia, Ubydul Haque, et al. Efficacy of ACTELLIC 300 CS, pirimiphos methyl, for indoor residual spraying in areas of high vector resistance to pyrethroids and carbamates in Zambia. Journal of Medical Entomology [Internet]. 2013 [cited 2021 May 26];50(6):1275-81. Available from: https://pubmed.ncbi.nlm.nih.gov/24843932/

15. Larval source management- A supplementary measure for malaria vector control: An operational manual 2013 [Internet]. [cited 2021 Aug 16]. Available from: https://www.who.int/malaria/publications/atoz/larval_source_management_2-pager_eng.pdf?ua=

16. Mugwagwa N, Mberikunashe J, Gombe NT, Tshimanga M, Bangure D, Mungati M. Factors associated with malaria infection in Honde valley, Mutasa district, Zimbabwe, 2014: a case control study. BMC Research Notes [Internet]. 2015 Dec 29 [cited 2021 Apr 21];8(1):829. Available from: https://doi.org/10.1186/s13104-015-1831-3

17. Refugees UNHC for. Refugee Housing Unit - Fact Sheet [Internet]. UNHCR. [cited 2021 Jun 17]. Available from: https://www.unhcr.org/en-lk/getinvolved/fundraising/5c1127d24/refugee-housingunit-fact-sheet.html

18. Sousa J de O, de Albuquerque BC, Coura JR, Suárez-Mutis MC. Use and retention of long-lasting insecticidal nets (LLINs) in a malaria risk area in the Brazilian Amazon: a 5-year follow-up intervention. Malaria Journal [Internet]. 2019 Mar 25 [cited 2021 Jun 16];18(1):100. Available from: https://doi.org/10.1186/s12936-019-2735-9

19. Brooks HM, Paul MKJ, Claude KM, Mocanu V, Hawkes MT. Use and disuse of malaria bed nets in an internally displaced persons camp in the Democratic Republic of the Congo: A mixed-methods study. PLOS ONE [Internet]. 2017 Sep 26 [cited 2021 Apr 16];12(9):e0185290. Available from: https://journals.plos.org/plosone/article?id=10.1371/journal.pone. 0185290

20. World Health Organization, Global Malaria Programme. Global technical strategy for malaria, 20162030. 2015.

21. U.S. President's Malaria Initiative Zimbabwe Malaria Operational Plan FY [Internet]. 2020 [cited 2021 Jun 16]. Available from: https://www.pmi.gov/docs/default-source/default-documentlibrary/malaria-operational-plans/fy20/fy-2020-zimbabwe-malaria-operational-plan.pdf?sfvrsn=6

22. Mundagowa PT, Chimberengwa PT. Malaria outbreak investigation in a rural area south of Zimbabwe: a case-control study. Malar J [Internet]. 2020 Dec [cited 2021 Apr 21];19(1):197. Available from: https://malariajournal.biomedcentral.com/articles/10.1186/s12936-020-03270-0 
23. Muchena G, Gombe N, Takundwa L, Tshimanga M, Bangure D, Masuka N, et al. Factors associated with contracting malaria in Ward 29 of Shamva District, Zimbabwe, 2014. South African Medical Journal [Internet]. 2017 Apr 25 [cited 2021 Apr 17];107(5):420-3. Available from: http://www.samj.org.za/index.php/samj/article/view/11887

24. Kureya T, Ndaimani A, Mhlanga M. Malaria Outbreak Investigation in Chipinge, Zimbabwe: A Casecontrol Study. Iran J Parasitol [Internet]. 2017 [cited 2021 May 17];12(3):423-32. Available from: https://www.ncbi.nlm.nih.gov/pmc/articles/PMC5623923/

\section{Figures}

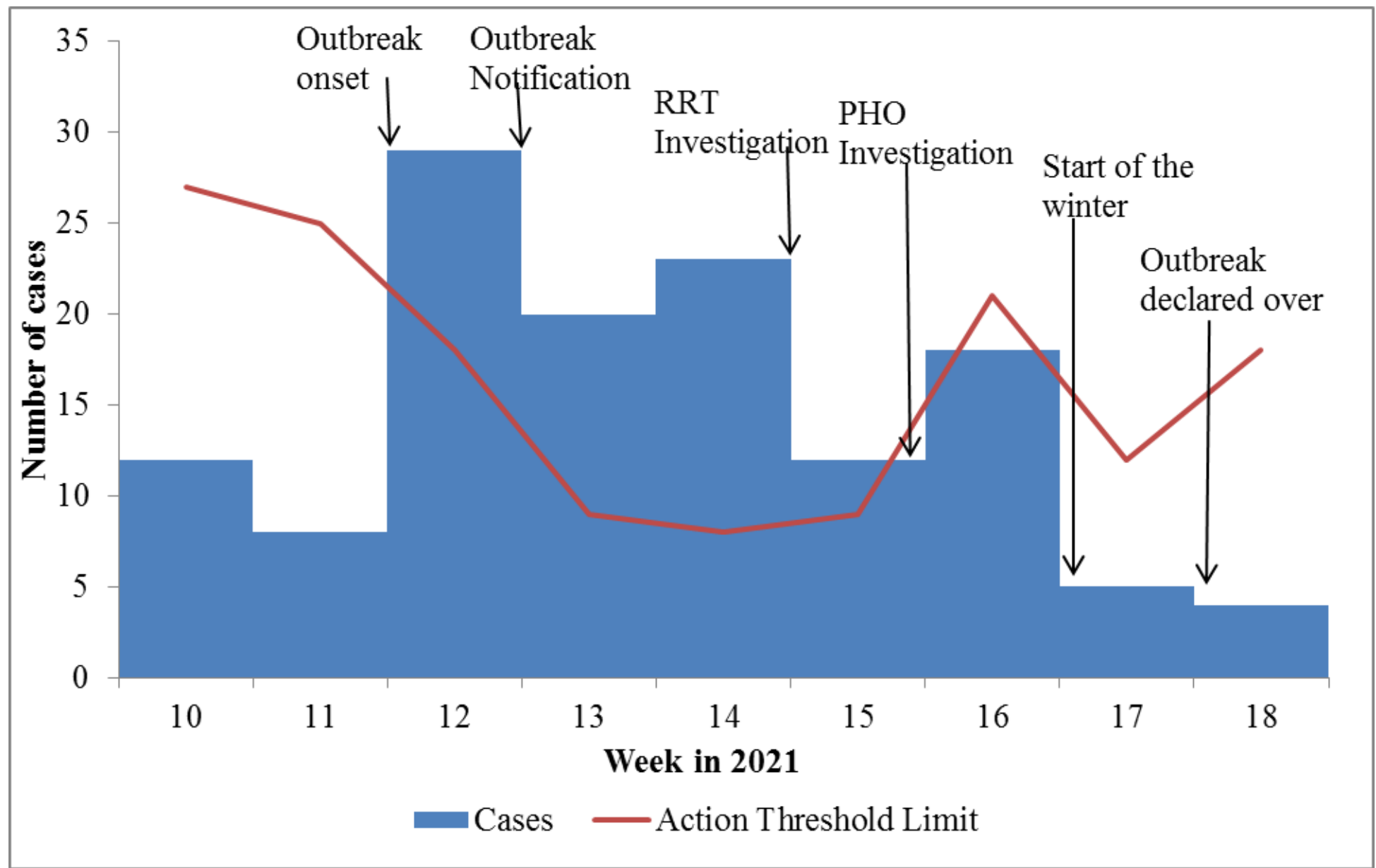

\section{Figure 1}

Epicurve for malaria cases at Tongogara Refugee Camp Clinic, Chipinge District, Zimbabwe, 2021 


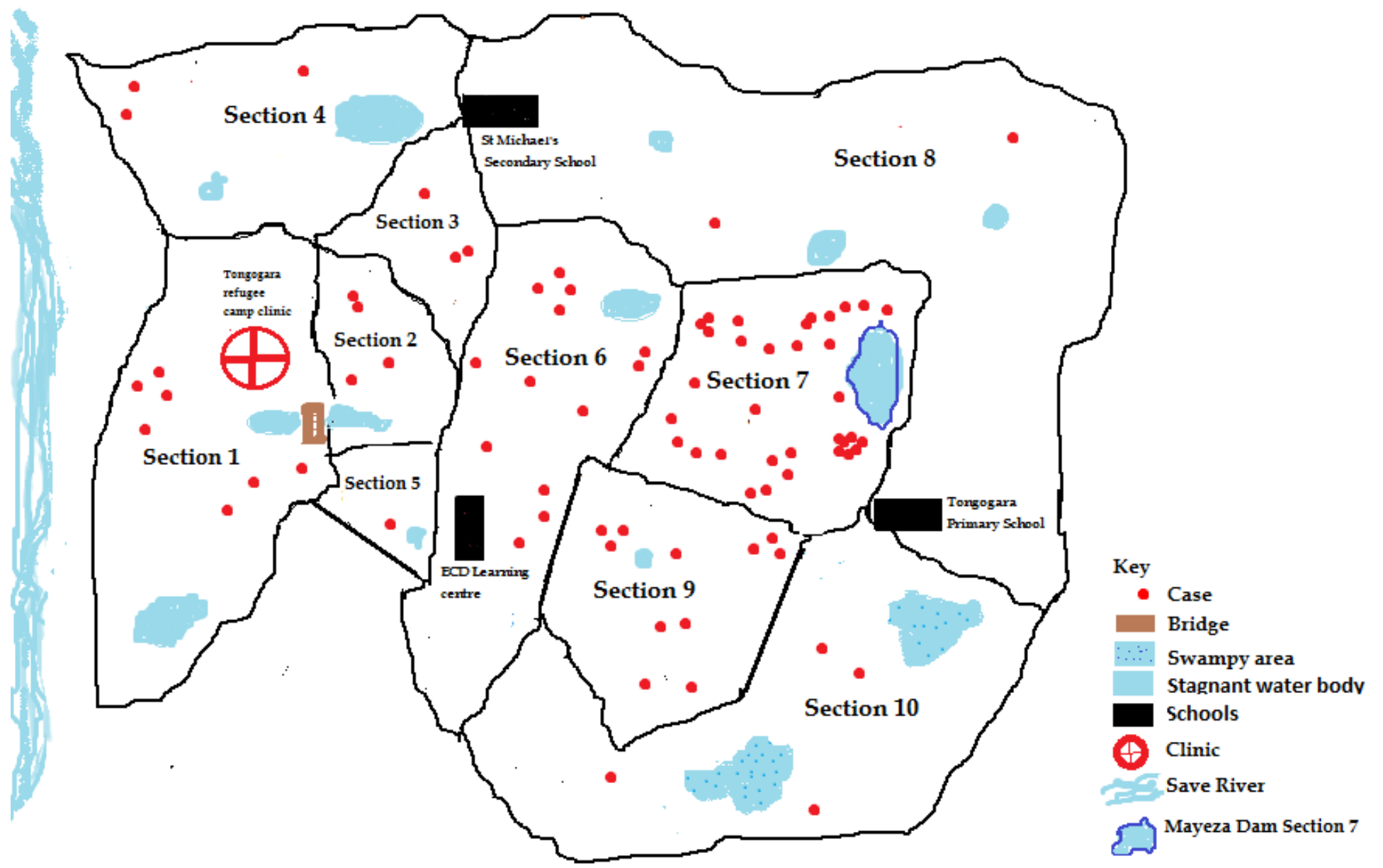

Figure 2

Spot map showing distribution of malaria cases at Tongogara Refugee Camp, Chipinge District, Zimbabwe, 2021 